Preprint of "Multilevel Embeddedness: The Case of the Global Fisheries Governance Complex", Social Networks 44 (2016) 281-294,

http://dx.doi.org/10.1016/j.socnet.2015.03.001, available from: www.elsevier.com/locate/socnet 


\title{
Multilevel Embeddedness: The Case of the Global Fisheries Governance Complex
}

\author{
James Hollway a,b,c,*, Johan Koskinen ${ }^{\mathrm{d}}$ \\ ${ }^{a}$ Nuffield College and Department of Politics $\mathcal{E}$ International Relations, \\ University of Oxford, New Road, Oxford OX1 1NF, United Kingdom \\ ${ }^{b}$ Chair of Social Networks, Department of Humanities, Social and Political Sciences, ETH Zürich, Clausiusstr. 50, CH-8029 Zürich, Switzerland \\ ${ }^{c}$ Center for Organisational Research and Social Network Analysis Research Center, \\ Università della Svizzera italiana, Via G. Buffi 13, CH-6904 Lugano, Switzerland \\ ${ }^{d}$ School of Social Sciences, The University of Manchester, Manchester M13 9P, United Kingdom
}

\begin{abstract}
This paper explores how bilateral and multilateral clustering are embedded in a multilevel system of interdependent networks. We argue that, in a complex system such as global fisheries governance, in which bilateral and multilateral relations are themselves interrelated, embeddedness cannot be reduced to unipartite or bipartite clustering but implicates potential multilevel closure. We elaborate expectations for ties' multilevel embeddedness based on network theory and substantive knowledge, and explore them using a multilevel ERGM. We find states' bilateral clustering is embedded in their shared membership in multilateral fisheries agreements, which is itself clustered around similar content and treaty secretariats.
\end{abstract}

Keywords: clustering, transitivity, four-cycles, multilevel networks, exponential random graph models, bilateral agreements, multilateral agreements, global fisheries governance

\section{Introduction}

How and why nodes tend to cluster has long been a subject of theoretical and empirical research in social networks. That nodes cluster their relations to form densely connected groups (Moreno and Jennings, 1938; Holland and Leinhardt, 1970; Davis, 1970; Opsahl and Panzarasa, 2009; Opsahl, 2011) has proven a robust finding across unipartite networks, consisting of ties between a single set of nodes (Simmel, 1955; Holland and Leinhardt, 1970), and in bipartite networks, in which ties are defined as occurring between two distinct nodesets (Borgatti and Everett, 1997; Robins and Alexander, 2004).

A number of theoretic motivations for the occurrence of clustering have been proposed ranging from structural balance (Cartwright and Harary, 1956), cohesion and embeddedness (Moody and White, 2003) to propinquity (Festinger et al., 1950). Clustering may also be seen as the outcome of the particular dependencies among tie-variables that we expect to see in social networks (Frank and Strauss, 1986). Different types of dependence assumptions may reflect the extent to which ties are more or less likely to cluster depending on how dyads are embedded in their local social environment (see Pattison and Snijders, 2013). Finding evidence for these dependencies in network data thus serves as a justification for employing methodological tools sensitive to such dependencies.

Clustering also matters substantively. Insofar as social relations provide conduits for transmitting information or influence,

\footnotetext{
${ }^{*}$ Corresponding author

Email address: jhollway@gess.ethz.ch (James Hollway)
}

clustering can have important ramifications for the diversity or reinforcement of information or influence along such ties (see e.g. Granovetter, 1973). On this basis, clustering has become a particularly pertinent research topic in the study of network governance, where such diversity or reinforcement is theorised to have important implications on the effectiveness of governance arrangements (Provan and Milward, 1995; Provan and Kenis, 2007; Robins et al., 2011; Lubell et al., 2014). Yet, while clustering is an important topic in such literatures and in both unipartite and bipartite contexts, few have investigated how clustering interconnects across interlocking unipartite and bipartite networks. Here we consider how different types of ties are embedded in each other by explicating their positions in a multilevel system.

To explore multilevel embedding, we examine a case from within the field of International Relations and network governance. The global fisheries governance complex provides an excellent example of where unipartite and bipartite networks interlock in a multilevel network governance context. It consists of states and the bilateral and multilateral fisheries agreements they establish between or among themselves to coordinate and cooperate regarding fish stocks that straddle or migrate across international maritime borders. ${ }^{1}$ This constitutes a multilevel network consisting of two types of nodes-the set of states $A$, and the set of multilateral fisheries agreements (MFAs) $B$-with different types of ties connecting nodes in the node sets. Here, the ties between states define a micro-level of interaction in the governance network, the affiliations with multilateral fisheries

\footnotetext{
${ }^{1}$ States may of course also take unilateral action to protect their enjoyment of resources, but this is not addressed here (Barkin and DeSombre, 2000).
} 
agreements establishes a meso-level link between the states and the macro-level of inter-related fisheries agreements. This multilevel network is a natural superordinate to the socio-ecological network of the fisheries governance complex (Bodin and Tengö, 2012). In our network, the ecological embedding is reduced to the states' relation to natural resources, such as fishing volumes and national tallies of threatened and endangered species, as well as the geo-spatial embedding of states.

These two types of agreement are structurally different in their negotiation and operation and typically fulfil different functions. The structural differences-bilateral agreements being limited to two parties, whereas multilateral agreements may engage many more-have profound implications for how these instruments are used. International law considers bilateral agreements to operate like contracts, offering parties the opportunity to negotiate terms dyadically. Multilateral agreements, though, are regularly employed as normative or "law-making" tools, for example the United Nations Convention on the Law of the Sea (UNCLOS) (see Shaw, 2003, 88-89). These structural differences then manifest themselves as functional differences too. Whereas bilateral fisheries agreements tend to concern either allocation of straddling stocks or access to under-exploited stocks, multilateral fisheries agreements tend to concern more collective, normative goals of optimal management and conservation of shared stocks. Because of these structural and functional differences, these different forms of agreement should be treated as constituting analytically distinct networks. On the one hand, states' dyadic ties through bilateral fisheries agreements (BFAs) can be expressed as a unipartite network (Kinne, 2013). On the other hand, to capture the structural information in states' membership affiliations in multilateral fisheries agreements, a bipartite representation is preferable.

But while they ought to be treated as analytically distinct, we argue that they should not be treated as independent because each case of a tie of one type existing may depend on a tie of the other type (see also Verdier, 2008; Zawahri and Mitchell, 2011). For example, the existence of a bilateral agreement between two states may affect their propensity to join the same multilateral agreements. Or, similarly, states may find that a shared multilateral agreement may encourage a complementary bilateral agreement or render it unnecessary. We therefore propose that actors' bilateral and multilateral institutional relationships ought to be treated as two parts of a single, multilevel network comprised of interlocking and thus interdependent unipartite and bipartite networks. Indeed, similarities between multilateral fisheries agreements constitute another unipartite network that may drive bipartite clustering. Since each of these networks interlock, we argue that they should be modelled together as an interdependent multilevel network to make the most robust inference on clustering mechanisms. In particular, the fact that multilateral treaties deal with collective issues means that states do not sign up to treaties that are similar unless the issues they deal with are of general interest. This gives rise to a particular form of multilevel clustering that suggest that a state cannot force the agenda of a multilateral treaties. This corroborates the evidence for the functional differences offered by associations with attributes of the states and the lack of multilevel alignment between bilateral ties and multilateral treaty content.

To analyse the embedding of ties within and across different types of networks, we draw on the exponential random graph (ERGM) family of models. Frank and Strauss (1986) developed ERGMs for one-mode networks from the so called Markov dependence assumption, which Snijders et al. (2006) elaborated by proposing parameters derived from the so called social circuit dependence assumption. Skvoretz and Faust (1999) proposed an ERGM for bipartite networks that was developed further by Agneessens and Roose (2008) and fully extended by Wang et al. $(2009,2013 a)$ to include recently proposed dependence models. ERGMS for exploring the joint analysis of ties between different types of nodes were considered already by Wasserman and Iacobucci (1991) and the seminal paper by Lazega et al. (2008), explicating the interrelations between ties of nodes at different levels, motivated the adoption of the new developments for ERGMs to multilevel networks by Wang et al. (2013b).

The rest of this paper is structured as follows. The next section introduces the three elemental networks that together constitute the multilevel network this paper concerns. It also reviews and discusses some descriptives for each network, speculating on some exogenous and endogenous mechanisms that may generate such descriptive features. Having introduced the multilevel network, the following section then introduces and discusses several multilevel mechanisms that we expect to play a role in generating the structure of our multilevel network, with special emphasis on cross-level clustering. We then turn to the results produced by modelling the component networks separately and jointly as a multilevel network, and discuss the results and what this tells us about clustering.

\section{A Multilevel Network}

This section describes the three interlocking, elemental networks of the multilevel global fisheries governance complex studied here. These networks "interlock" around the two distinct nodesets. On a micro-level we have ties between states with a potential set of ties that we denote $A A$; on the macro-level we have ties between the MFAs with a potential edge set $B B$; and, finally a meso-level connecting the nodes in $A$ with the nodes in $B$ giving a set of potential bipartite edges $A B$. We use $A A$, $A B$, and $B B$ as a notational shorthand for the Cartesian products but the set of possible non-redundant ties are more correctly defined as $\left(\begin{array}{l}A \\ 2\end{array}\right), A \times B$, and $\left(\begin{array}{l}B \\ 2\end{array}\right)$, respectively. Following Wang et al. (2013b) and Wasserman and Iacobucci (1991), we may define the blocked adjacency matrix for the full multilevel network in terms of

$$
X=\left(\begin{array}{cc}
X_{A \times A} & X_{A \times B} \\
X_{B \times A} & X_{B \times B}
\end{array}\right)
$$

The upper left-hand block thus represents the ties between states, the upper right-hand block represents the meso-level ties, and lower right-hand block represents the macro-level ties between MFAs. In the following we describe the data upon which the different types of ties and nodes are based. 


\subsection{Bilateral Fisheries Agreements - AA Network}

The first nodeset, $A$, consists of all states in the interstate system. States are the primary actors in global fisheries governance and, since articles 124-125 of the United Nations Convention on the Law of the Sea (UNCLOS) states that all states have the sovereign right to access and fish the high seas, all 195 sovereign states are included, including landlocked states (see also Shaw, 2003, 541-542). While this results in a rather high level of isolates, some landlocked states do still participate in bilateral fisheries agreements, say to regulate fish stocks straddling inland lakes or rivers, and sometimes multilateral fisheries agreements to support multilateral norms. We also included other entities recognised as relevant to global fisheries governance, such as Chinese Taipei, the Cook Islands, and the European Union (EU).

The ties in $A A$ consist of bilateral fisheries agreements (BFAs) between states (see Fig. 1). BFAs tend to represent one of two main themes. For states with abutting maritime borders, BFAs often clarify the nature and extent of these borders, or determine the allocation of fish stocks that straddle these maritime borders, such as between China and Vietnam (see also Xue, 2005). For states without adjoining maritime borders, bilateral fisheries agreements tend to involve rich, distant water fishing nations, such as Japan or the EU, trading aid for cheap access to fisheries in less-developed island states (Petersen, 2003). ${ }^{2}$

Data on these ties were compiled by merging the two most comprehensive sources for international environmental agreements, ECOLEX (2011) and the International Environmental Agreement (IEA) database of Mitchell (2013), and complementing the resulting dataset with archival research. The resulting Global Fisheries Governance dataset (GFG) improves on both ECOLEX and IEA. It adds $130 \%$ more treaties than ECOLEX and $20 \%$ more treaties than IEA, translating into $40 \%$ more information on states' ties to these treaties than ECOLEX and $70 \%$ more ties than IEA. In terms of bilateral treaties (which comprise nearly $80 \%$ of all treaties, but only about $20 \%$ of all ties), the merger introduced $140 \%$ more bilateral treaties than ECOLEX and $43 \%$ more than IEA.

The above descriptions motivated the inclusion of four covariates as potentially relevant to explaining the $A A$ network. First, we include the number of THREATENED SPECIES a state has in its marine area. This data was collected from the World Bank (Froese and Pauly, 2008). We might expect states that have threatened species at home to want to protect these fish stocks from further exploitation (and perhaps secure access to more robust fish stocks elsewhere). Second, we use the amount of fish landed by each state to indicate a state's involvement in the exploitation of global fish stocks. This FISHING data was drawn from the Food and Agriculture Organisation's (FAO) data aggregated in the programme FishStatJ (FAO, 2011). Third, we include GDP (logged thousands) to explore how states' fiscal capacity enables them to enter into and maintain many different bilateral relationships. Justification for the inclusion of this effect can be gleaned from simply inspecting Fig. 1, in which the heightened

\footnotetext{
${ }^{2}$ The EU has tried to introduce sustainability as a principle into its 'fisheries partnership approach' though. See Witbooi (2008).
}

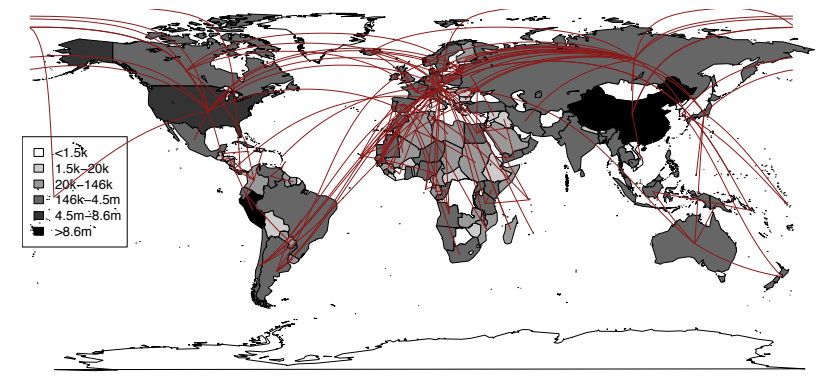

Figure 1: Bilateral Fisheries Treaty Map: Bilateral fisheries agreements between states $i$ and $j(i, j \in A)$ are represented by a line following the shortest line from the midpoints of each state's main territory around the earth's curvature. States are coloured by the number of fish each state reports having caught

activity of the richer states of the developed world can clearly be seen. We also investigate whether there is any systematic homophily or heterophily in the capacity of any particular dyad. This data was recovered from the UN and the World Bank.

Since states are embedded in a spatial dimension, we also include a dyadic covariate to control for the distance between two states. In addition to the possible alignment of $A A$-ties and sharing maritime borders, Fig. 1 suggests there is a general tendency for short-range ties. We follow the approach of Daraganova et al. (2012) for incorporating distance into ERGMs, namely using logged Euclidean distance as a dyadic covariate, a functional form that has also been used to mimic gravity-dependence in networks of states (see Koskinen and Lomi, 2013).

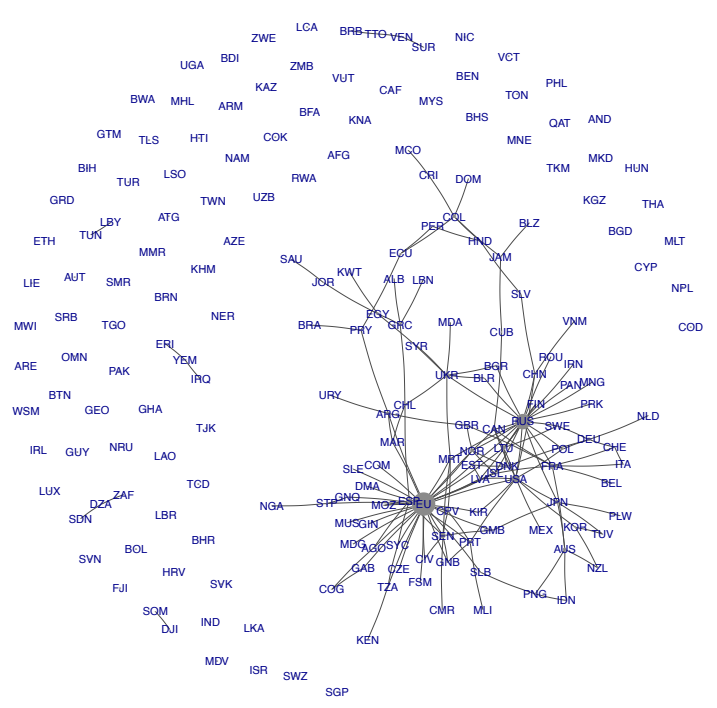

Figure 2: Bilateral Fisheries Agreement Network: Dyadic bilateral fisheries agreements between states where node size is proportional to degree centrality. 
In addition to these monadic and dyadic exogenous influences on bilateral agreement formation, some centralisation and clustering is visible from the spatially-disembedded structure of the network in Fig.. 2. In particular, Fig.. 2 reveals how dominant in terms of bilateral activity the EU and Russia are here. Geography may explain this in part, but a return to Fig. 1 also shows us, for instance, how many of the EU's BFA interlocutors are non-adjacent African states. This structural feature is driven primarily by the EU's policy of establishing fisheries partnership agreements to gain access to distant, developing fisheries. Beyond these two dominant nodes, there are other, more regionally central actors, but we also see a lattice-like structure emerge on the periphery, which is again suggestive of the influence of maritime geography and adjacency or at least propinquity.

\subsection{Multilateral Fisheries Agreements - AB Network}

Whereas states $(A)$ establish bilateral agreements (the $A A$ network) dyadically, multilateral agreements are established collectively. We treat the multilateral fisheries agreements (MFAs) in this context as a separate nodeset $(B)$, and the ties of a bipartite network $(A B)$ between these two nodesets as consisting of a "web of [multilateral fishing] treaties covering the preservation of the marine environment" (Shaw, 2003, 554). We hold MFAs as separate from BFAs because multilateral treaties are usually "concluded in pursuit of a collective interest that transcends the individual interests of the contracting parties" and are thus rarely decomposable into bilateral components (Pauwelyn, 2003). This distinction is also something that will inform our research questions in the analysis. Moreover, structural information would be lost if we were to project multilateral treaties into a one-mode network (Borgatti and Everett, 1997; Opsahl, 2011).

We follow both IEA and ECOLEX in including conventions, agreements, amendments, protocols and exchanges of letters, all of which are treaties (Shaw, 2003, 88), allowing for the structure to capture all types of agreement (Mitchell, 2013; ECOLEX, 2011). ${ }^{3}$

Ties are considered present when a state, $a$, has signed, ratified, acceded or succeeded to or been approved into a multilateral fisheries treaty, $b$ (see Shaw, 2003, 817-821). This study does not distinguish between signature and ratification nor does it consider the longitudinal aspects of the data here. As with $A A$, data on the $B$ nodes and the $B B$ ties were collected from two sources: ECOLEX (2011) and IEA (Mitchell, 2013). Merging the two made a more comprehensive dataset than either, with 90\% more multilateral treaties than ECOLEX and 14\% more multilateral treaties than IEA.

The EU is not technically a state but still is an important actor in the fisheries governance structure. We treat it as a state actor but given that the tie-formation of the EU as an actor is likely to follow different processes from other nodes, we treat the ties of the EU as exogenous and fixed. Similarly, there are a number of MFAs that have more than half of the 195 states as signatories.

\footnotetext{
${ }^{3}$ A subset of 200 out of 225 MFAs were finalised after we dropped those for which we had no structural data-occasionally the case for very old or very new MFAs - or for which we could not collect texts, since the treaties' texts are important for the construction of the $B B$ network described below.
}

In particular, the UN convention UNCLOS has been ratified by 174 states. These MFAs have potentially very important roles in relation to other MFAs but given their special status and their ties being contingent on other memberships, the affiliation ties of these MFAs do not lend themselves to modelling in terms of endogenous network processes. We therefore chose to model the $A B$ network conditional on these ties.

Fig. 3 presents a depiction of this network. States are represented as olive circles and MFAs as red squares. Discounting the three isolates (Andorra, San Marino, and Azerbaijan) the remaining structure is rather dense, complex and overlapping, with a clear core and periphery evident.

The core and periphery are also evident in very long tails to the degree distributions for $A B$ and $B A$ (the degree distributions are graphically represented in the Results Section in Fig. 11). Part of the skewness is accounted for by the EU on the state side, and by UNCLOS and other MFAs like it on the MFA side. Tie-formation for the latter, for the very large MFAs, is likely to follow processes different from the endogenous tie-formation processes that apply to the other MFAs. As mentioned above, the UN treaty UNCLOS, for example, includes almost all states. For the purposes of analysis we thus treat ties of these large MFAs as exogenous and fixed. We identify the MFAs to be treaties as exogenous as those that have roughly more than $20 \%$ of the states as signatories.

Among the high-degree states we have a number of (predominantly) developed states with a central role in the fisheries governance network. Some have a traditionally leading role, such as France (70 ties), but they all share that they dominate and set the agenda for international fisheries and although there is a large dispersion in the degrees among these actors, there is a clear distinction between states with 20 or less ties (India top) and states with more than 20 ties (People's Republic of China bottom). In lieu of accounting for this degree heterogeneity parametrically (Schweinberger and Handcock, 2012) we exogenise extremely high degree nodes (Robins and Lusher, 2013, 184), or "big fish", to focus on "small fish" (those with more common involvement patterns). We thus develop our research questions for the $A B$ network with a view to explaining the behaviour of the "small fish" given the established affiliations of the "big fish" (cf. Lazega et al., 2008).

As with $A A$, we include several salient covariates. First, we consider GDP as providing the capacity to enable states' participation in this network. Second, we investigate whether states having many THREATENED SPECIES motivates their participation in this network.

\subsection{MFA Content Similarity Network - BB Network}

Multilateral treaties do not exist in a vacuum, but their content is conceived and negotiated in relation to other treaties, and states select which multilateral agreements to join with reasonable knowledge about how those documents interrelate (see Jupille et al., 2013). The third network, $B B$, consists of ties between the MFAs. Like any complex document, multilateral treaties are linked in many interesting and meaningful ways, including shared authors, location, and date. However, one of the distinct features of multilateral treaties is that, more than 


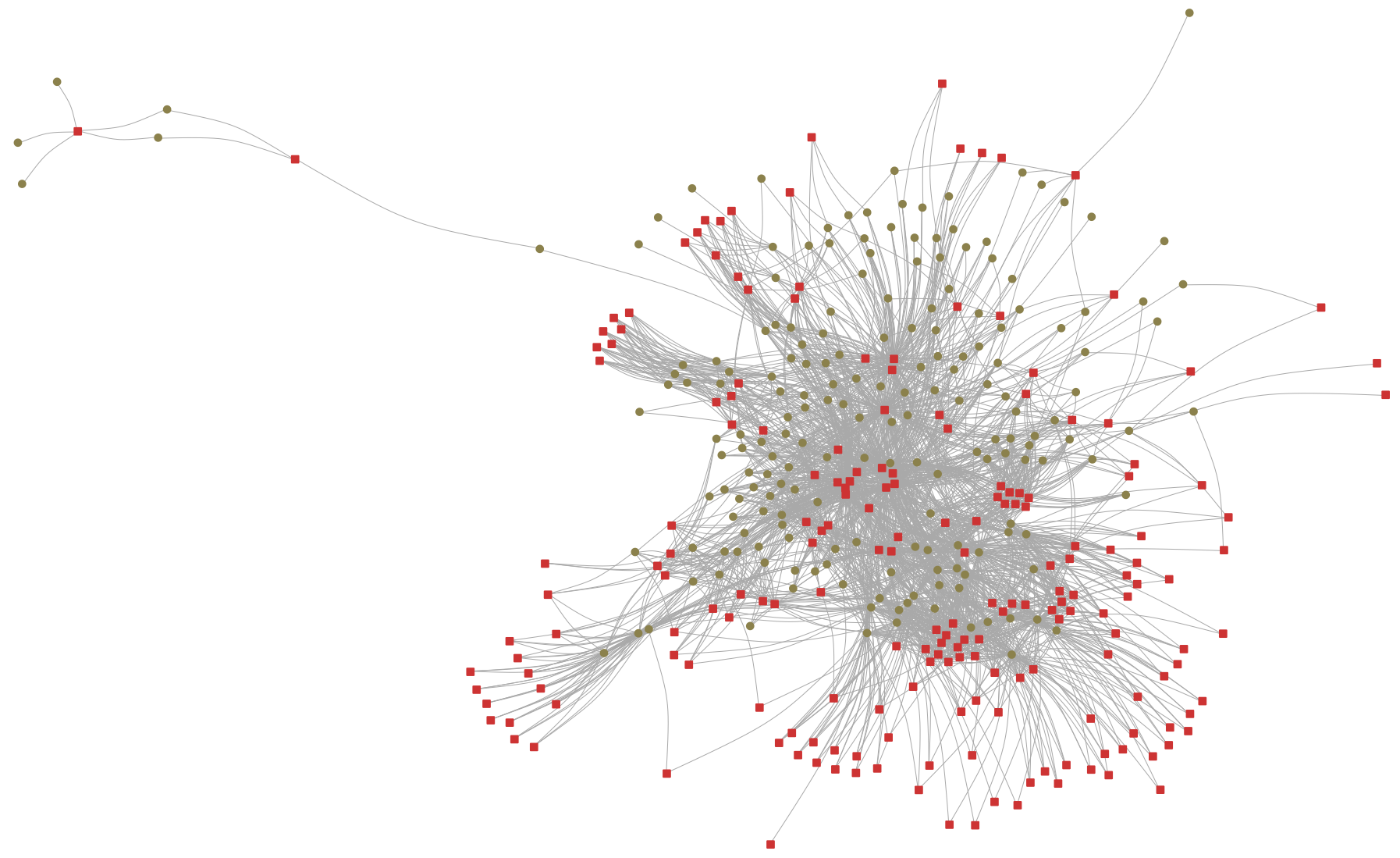

Figure 3: Multilateral Fisheries Treaty Network: States (olive circles) affiliated with multilateral fisheries agreements (red squares). Three isolates are not depicted.

bilateral treaties, they are responsible for the creation or codification of much international customary law and its normative evolution (Carr and Scott, 1999; Chalamish, 2009; Kim, 2013). The normative structures in which such treaties are embedded are important for it is through their normative interlinkages that multiple agreements complement or come into conflict with one another (see e.g. Zelli and van Asselt, 2013). Here we consider three main ways in which the complementary or conflictual relationship between multilateral fisheries treaties can be expressed so as to make an informed choice of a $B B$ network.

First, since MFAs are seldom global (UNCLOS being an exception), whether two treaties may complement or conflict with one another will depend first on whether they relate to the same geographic areas; in other words, whether they have the same or similar scope. We coded scope by combining information about the geographic area MFAs operated in respect of from ECOLEX and IEA. This constituted a network in which MFAs were related or tied when they share a primary geographic area (coded to include different scopes such as the Baltic Sea or the High Seas). This resulted in a dandelion structure that can be seen in the top left plot of Fig.. 4.

Second, MFAs often cite earlier MFAs in their preamble. As with academic citations, there can be multiple motivations for such referencing practices, including association with more popular treaties, validation for normative arguments, as part of a process of cumulative law-making, or as an amendment or addition to contemporary international law. A similar strategy was carried out by Kim (2013). Unlike Kim however, we follow Mitchell (2013) in including all treaty types and rely in part on their classification of treaties into distinct normative lineages with clear sequencing to construct an agreement-amendment-addition hierarchy to the citation structure of these treaties. This was complemented by the addition of some ties through ECOLEX (ECOLEX, 2011). The result is a sparse network of MFAs, often connected linearly with some early branching as can be seen in the centre plot of Fig.. 4.

Third, MFA texts often overlap in content. Treaties may address similar or quite different subject matter independently of whether it occurs in the same lineage or refers to the same geographic area. We are thus also interested in a relational network of how the MFAs relate to each other in terms of the issues they deal with. We measure this relation through investigating their pair-wise textual similarity.

To construct a network of similarities between treaties' texts it was first necessary to collect the documents of all MFAs. $98 \%$ of all treaty texts in the original dataset were found. These texts underwent some cleaning, and then the textcat package in $\mathrm{R}$ was used to construct a matrix of Jensen-Shannon divergences between the $n$-gram frequency distributions of all MFA texts (Hornik et al., 2013). ${ }^{4}$ Jensen-Shannon was chosen over com-

\footnotetext{
${ }^{4}$ Where an $n$-gram in one text profile is missing in the other, this is given a small, positive absolute frequency $(1 e-6)$ for algorithmic reasons.
} 


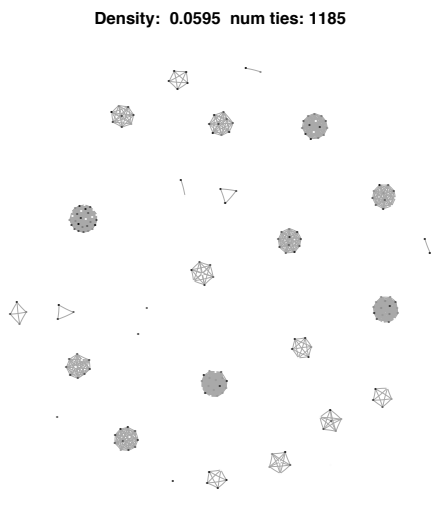

corr : $0.0209 p(>): 0.002, p(<): 0.999$

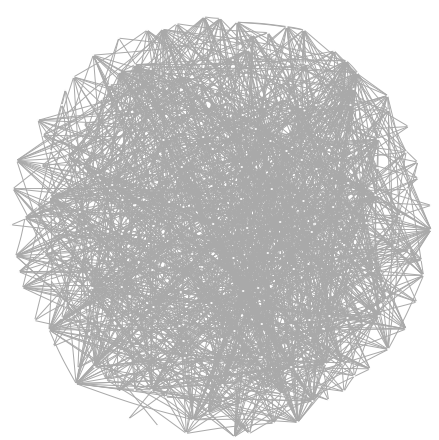

corr : $0.0071 \mathrm{p}(>): 0.172, \mathrm{p}(<): 0.848$

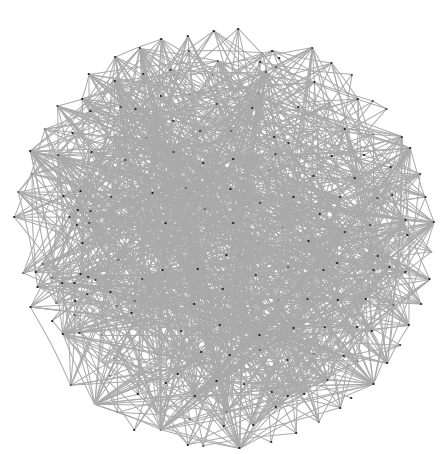

corr : $0.0209 \mathrm{p}(>): 0.002, \mathrm{p}(<): 0.999$

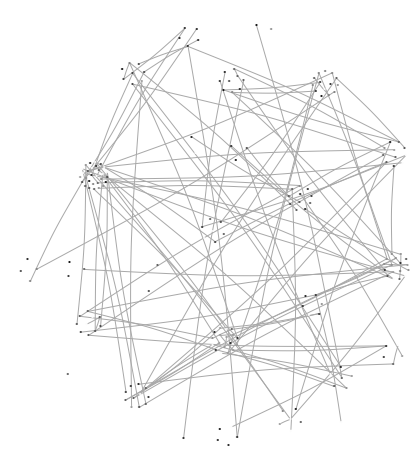

Density: 0.0028 num ties: 55.5

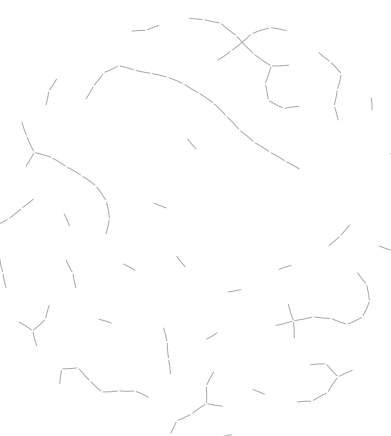

corr : $0.1219 p(>): 0, p(<): 1$

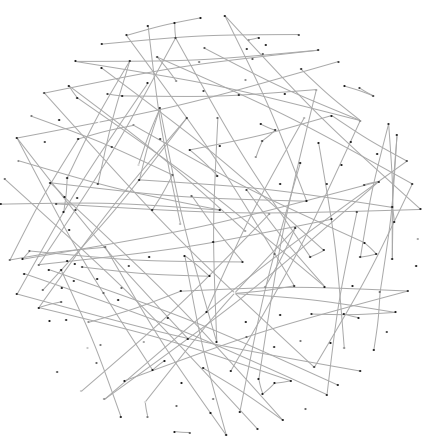

corr : $0.0071 p(>): 0.172, p(<): 0.848$

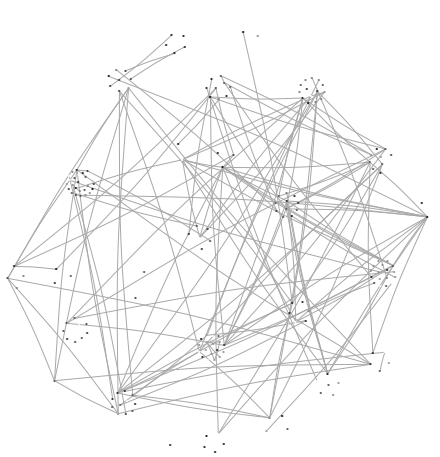

corr : $0.1219 p(>): 0, p(<): 1$

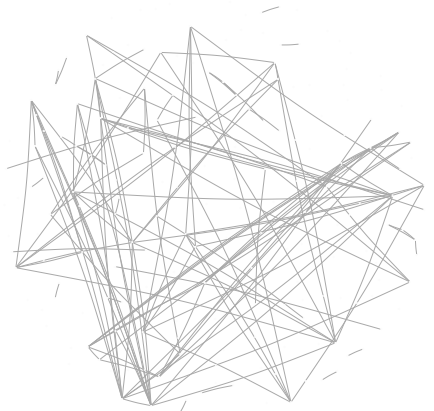

Density: 0.0069 num ties: 138

Figure 4: Networks between Multilateral Fisheries Agreements: From top to bottom same geographical area, same lineage, and textual similarity (content). Layouts are derived from geographical area, same lineage, and textual similarity for left, middle, and right columns respectively. QAP correlations provided for row and column relation

petitors for its twin advantages of being symmetric and finite (ranging between 0 and 1). Using the dichotomised association matrix as our adjacency matrix for the $B B$ network, rather than using a number of clusters, say, affords a more granular interpretation than a regular hierarchical cluster analysis. A tie was deemed to exist if the distance $d(i, j)<0.01$, chosen to balance density and detail. In this way, the terminological similarity network represents the degree to which two MFAs' texts call similar vocabulary resources in the pursuit of their aims, thereby accumulating to content. The sociogram of the resulting network is given in the bottom right panel of Fig. 4. As can be seen there, this network is sparser than the geography network (top left) but denser than the amendment network (middle).

Fig. 4 presents the three forms of MFA interlinkage along the diagonal. All three networks yield meaningful relations on $B$ and to get a sense of the similarity between the networks, we plot 
them with exchanged layout. The off diagonal plots in Fig. 4 take the layout from the rows and the ties from the columns to give a visual clue to the degree of overlap between these three networks. The QAP correlation between same geography and the other two networks is low (0.02 and 0.007 for lineage and content respectively) We find that there is some correlation between lineage and geography, as well as a significant correlation (0.12) between lineage and content. That the association between lineage and content is strong is to be expected as an MFA amends another MFA precisely because of the content. The content network is however more general in that it is able to pick up parallel paths addressing similar issue without amendment.

As an example of meaningful alignment as well as meaningful discrepancies, let us consider four dyads of ties between $b_{1}$ and $b_{2}$ where there is:

1. no tie in either lineage or content networks,

2. a tie in the lineage network but not in the content network,

3. a tie in both networks, and

4. a tie in the content network but not the lineage network.

An example of (1) is the absence of any tie between "Amendments To The Agreement For The Establishment Of The IndoPacific Fisheries Council 1958" and "Amendments to the Agreement For The Establishment Of A General Fisheries Commission For The Mediterranean 1997". Despite both being amendments to regional agreements, these treaties operate for distinct regions and represent two different styles of amendment: the former lists just a few phrases that need to be amended in the earlier document, whereas the latter recounts the entire original text with additions and removals embedded.

An example of (2) is the "Agreement On The Organization Of The Permanent Commission Of The Conference On The Exploitation And Conservation Of The Maritime Resources Of The South Pacific 1952" and "Regulations Governing Permits For The Exploitation Of The Maritime Resources Of The South Pacific 1955". Here they are both clearly in the same lineage of MFAs - they both concern the South Pacific-but address distinct topics; the former establishes a Permanent Commission for the South Pacific, whereas the latter concerns more prosaic matters such as permits.

An example of (3) is the "Agreement between Denmark (on behalf of Greenland), Iceland and Norway concerning the Stock of Capelin in the Waters between Greenland, Iceland and Jan Mayen 1994" and "Agreement Between Norway, Greenland/Denmark, And Iceland About The Capelin Stock In The Area Between Greenland, Iceland, And Jan Mayen 1998”. Both are in a lineage of MFAs concerning Norway - Iceland - Greenland (Denmark) capelin, and the latter text largely takes the earlier text as a template, updating just a few measures such as the proportions of the Total Allowable Catch (TAC) afforded each of the three states.

Lastly, an example of (4) is the "Agreement For The Establishment Of The Intergovernmental Organization For Marketing Information And Cooperation Services For Fishery Products In Africa 1991" and the "Constitution Of The Centre For Marketing Information And Advisory Services For Fishery Products In The Arab Region 1993". One can immediately tell from the titles of these two MFAs that they share subject matter - marketing information for fishery products - possibly even representing a normative/policy diffusion, however the lineages are quite distinct for they are involved in reasonably separate geographic areas.

In addition to the via media that the content similarity network offers in terms of density and clustering, these four cases illustrate why the content similarity network operates as the best proxy for the normative conflicts and complementarities the literature is concerned with here. Hence we use the content similarity network as our $B B$ network.

\section{Multilevel Clustering}

These three networks could be modelled separately without taking the interdependencies among the different types of ties into account. This then assumes that the ties in the different networks are completely independent of each other. However, Lazega et al. (2008) demonstrated the analytical advantages of explicitly studying how different levels interact and indicated the added insight that might be obtained from considering ties across different levels jointly as a multilevel network. Aside from the additional insights that cross-level interactions offer, Wang et al. (2013b) also demonstrate the indirect effects of cross-level effects on the separate networks marginally. Taking the interdependence of the micro, meso, and macro level into account explains properties of these levels considered separately. In other words, the cross-level effects do not only model how the different levels co-depend, they also demonstrate how effects on one level (such as clustering) may be derived from another level.

Empirically, there is little experience with parsing out these dependencies when all the levels are modelled simultaneously. We here specify a number of specific cross-level effects for determining the clustering across micro, meso, and macro levels in terms of ties embedded on all levels. Based on the preceding discussion we shall aim to define what kind of structural patterns we would expect to be associated with what particular mechanisms. We focus mainly on how the different types of clustering, the way in which different types of ties are embedded in other ties, cast light on the different functions and purposes of different types of ties.

Based on our discussion in previous sections, we argue that states use bilateral and multilateral ties for different purposes. Our main aim is to show how this structures different forms of clustering. However, this difference in functionality is also evidenced in covariate-related effects as well as other structural characteristics. Important determinants for bilateral ties will be the state's capacity (here measured by GDP) and the state's economic interest in fishing (measured as their fishing volume). These considerations, GDP and fishing, will not factor in for multilateral ties, instead we expect such ties to be related to the common good, such as a concern for threatened species. These different purposes would also suggest that there is a negative association between states' bilateral and multilateral degree. Based on these premises we will also develop an argument for 
how the usage of ties at different levels moderates unipartite, bipartite, and multilevel clustering.

In the following we will develop our research questions in terms of predictions for specific network statistics in an exponential random graph framework (Lusher et al., 2013). We aim to test the hypothesized mechanisms behind the subgraph counts by including these network configurations in ERGMs, and assess whether their associated parameters are positive, negative or zero.

\subsection{One-Mode Clustering}

\subsubsection{Bilateral clustering and multilateral ties}

One-mode or unipartite clustering has a long tradition in social network research (Simmel, 1955). In unipartite networks, clustering is usually measured based on the presence of transitive or closed triads (Holland and Leinhardt, 1970). In the ERGM framework, transitive closure is typically seen as a result of the types of dependencies that typically guide the formation of tievariables. In particular, the social circuit model for ERGMs that includes configurations of the type in Fig. 5(b) and 5(a)), have been proposed as empirically valid models that capture both tendencies to centralisation and triadic closure (Snijders et al., 2006). A model including statistics for both configurations, is able to tell us whether there is a significant tendency towards triadic closure, given the number of two-paths, i.e. whether ties tend to "cluster" given other endogenous processes.

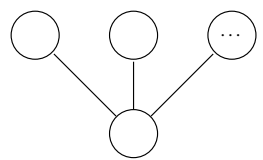

(a) Bilateral Centralisation (AS)

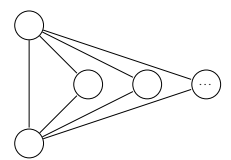

(b) Bilateral Clustering (AT)

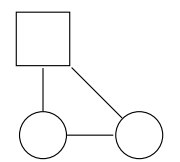

(c) Bilat.-Multilat.

Clustering (TriangleXAX)
Figure 5: Configurations Associated with Bilateral Clustering: Circles represent states and squares represent multilateral fisheries agreements.

Kinne (2013) finds evidence for a tendency towards closure using a stochastic actor-oriented model. Kinne argues that there are more closed triads than expected from other structural and covariate-related explanations because there are informationand externality-based mechanisms that are endogenous to the evolution of the network structure. He finds this effect across multiple networks of international relations, but his results suggest that triadic closure/transitivity is strongest in the case of bilateral fisheries agreements.

Our argument however is that bilateral fisheries agreements (BFAs) are not negotiated or settled independent of other modes of international cooperation on the same issues, such as through multilateral fisheries agreements (MFAs). We speculate that indeed some of the clustering that Kinne observes may instead be driven by states seeking to complement relationships with other states established by shared membership in multilateral fisheries agreements. In other words, shared membership in MFAs may be driving BFA clustering; BFA clustering may be incidental to shared MFA membership, because they often serve ancillary, instrumental purposes - two states can constitute a bilateral agreement based on an MFA but they cannot, by virtue of being just a dyad, constitute an MFA.

We operationalise this effect as closure spanning these two networks, $A A$ and $A B$, as depicted in Fig. 5(c). While this effect invokes only two state nodes (circles), rather than the three or more present in the effects mapping bilateral centralisation and clustering, because MFAs involve by definition three or more parties we propose that this effect will explain away the clustering Kinne observes. Thus we predict that $X_{A A}$ when fitted separately will indicate a positive tendency towards Bilateral clustering (AT) but once we control for Bilat.-Mulltilat. Clustering (TriangleXAX), AT will disappear.

\subsubsection{Clustering of MFAs}

MFAs are connected in many different ways (such as geography and lineage) but the most general way in which they are connected is in terms of content similarity. Since the content similarity network as defined here is roughly based on a distance metric, this implies (by the triangle inequality) clustering of the sort shown in Fig. 6(a). Yet, we do not expect to see many MFAs that broker content domains, such as the central node in the configuration shown in Fig. 6(b). For example, while MFAs that are geared towards conservationist values may well share textual similarities with one another, none are then likely to then also share much content with MFAs that concern optimising resource usage. In other words, we expect this clustering to be community defining and not diffuse. In ERGM specifications, there is a so-called alternating edge-triangle effect (the appended edge in Fig. 6(b) is made 'alternating'). In Fig. 4, a number of 'coat-hangers' (triangle configurations with an additional edge leading from one of the nodes) are visible but more than one appended edge is rare. This suggests that 'brokerage' texts are rare.

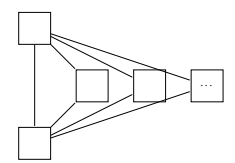

(a) MFA

Clustering (AT)

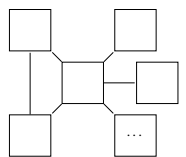

(b) MFA brokerage (ATE)
Figure 6: Configurations Associated with One-mode Clustering of MFAs

Next, while we expect that $A B$ ties may induce closure of $A A$ ties through cross-level closure (Fig. 5(c)), which in turn may explain one-mode closure in the $A A$ network (Fig. 5(b)), we do not expect to see spurious clustering in the $B B$ network of a similar kind. In other words, we do not expect TriangleXBX (Fig. $8(\mathrm{e})$ ) to explain one-mode clustering (AT) in $B B$. If this were the case it would mean that multiple MFAs shared content because they had the same state in common, something which would imply that this one state dictated the content of the MFAs. We also do not necessarily expect to see clusters of states negotiating the contents of MFAs in such a way so as to fully explain the clustering in the $B B$ network. We therefore predict that the one- 
mode clustering represented by Fig. 6(b) will remain when the cross-level closure effect TriangleXBX (Fig. 8(e)) and clustering around issues (Fig. 8(c)) is taken into account.

\subsection{Two-Mode Clustering}

In bipartite or affiliation networks, such as the $A B$ network, clustering is typically measured in terms of four-cycles or joint memberships such as that expressed in Fig. 7(a) (see Robins and Alexander, 2004; Borgatti and Everett, 1997). Here we consider two potential moderators to such clustering. First, it may be that the many such four-cycles are generated by some top-level nodes, as targets in an affiliation network, serving as better foci or social settings than others, generating opportunities for further interaction which, ultimately, manifests itself in terms of bilateral clustering (Robins and Alexander, 2004; Wang et al., 2009). This is represented here as whether some MFAs establish and maintain a treaty secretariat, which record activities and provide venues for regular interaction, thus sometimes going beyond a mere collection of actors (Breiger, 1974). Second, states may cluster around particular MFAs because they are more textually similar, which we read as having similar content and form. To study this requires that we consider how the bipartite ties are embedded in the multilevel structure.

\subsubsection{Nodal moderators of bipartite clustering}

A key aspect of the literature on clustering in affiliation networks is that shared affiliations provide foci or social settings that promote further shared affiliations or even new foci. We argue here that some MFAs facilitate clustering more than others because the design of the agreement provides for the establishment of a secretariat. These secretariats may fill various purposes related to the durability, adaptability and efficacy of the institutional rules provided for in the MFA, but they also provide sites, foci, or social settings that bring actors together for sharing information on, among other things, the utility of joining other MFAs.

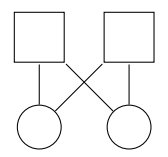

(a) Shared

Choices (4Cycle)

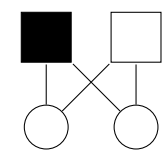

(b) Shared

Managed

Choices (X4CycleB1)

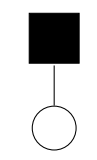

(c) Managed Popularity (XEdgeA)
Figure 7: Secretariat Clustering Effects: Circles represent states and squares represent multilateral fisheries agreements. Coloured nodes have secretariats whereas white nodes are ambiguous; i.e. they may have an associated secretariat or not.

Lubell et al. (2014) analyze how bipartite clustering is associated with different types of nodes. They draw on Berardo and Scholz (2010) to suggest that actors and institutions function to solve cooperation problems if they are embedded in a high number of four-cycles. By picking out nodes post hoc that are particularly embedded in four-cycles, they tentatively identify what nodes are more involved with coordination problems and information transmission. Secretariats are established and set up in order to, among other things, explicitly deal with coordination and information transmission. Thus we predict that there will be bipartite clustering around MFA secretariats with a positive effect for configurations like Fig. 7(b), controlling for lower-order effects such as the overall attractiveness of secretariat-related MFAs shown in Fig. 7(c).

\subsubsection{Multilevel embeddedness of bipartite clustering}

The second factor that affects bipartite clustering here are similarities in MFAs' content. This matters because we might expect that states generally join MFAs that are similar to those they have already joined. After all, states are likely to find MFAs that are similar to those they have already joined more likely to be salient to them, in line with their revealed preferences, and involve fewer additional costs beyond those they have already committed to in the original MFA. Such an effect is depicted in Figure 8(b), controlling for the general attractiveness of MFAs that appear similar to other MFAs (Figure 8(a)).

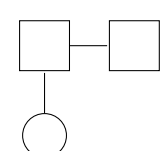

(a) Choose Similar (Star2BX)

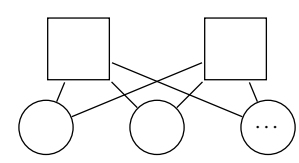

(c) Multilateral

Clustering

(GW Shared A Nodes)

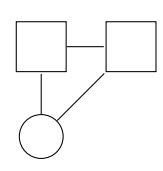

(b) Similar

Choices (TriangleXBX)

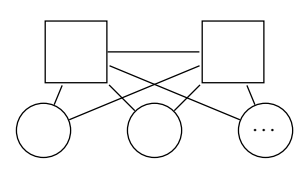

(d) Similar Multilateral Clustering (ATXBX)
Figure 8: Multilateral Clustering Effects: Circles represent states and squares represent multilateral fisheries agreements.

However, including this effect (or these two effects) alone would have some odd outcomes because a positive effect of states making similar MFA choices (TriangleXBX) would result in the accumulation of local triangles XBX, but says nothing about how these configurations are embedded. First, without an effect that defines how these choices overlap, it is possible that a positive TriangleXBX parameter could result in disembedded triangles such as that depicted in Fig. 9(a). The problem with such a result is that this is empirically impossible: multilateral fisheries agreements are not established unilaterally but by multiple parties. Second, a result in which they overlap but evenly chain is also unlikely. Even where multiple parties are engaged, such configurations would suggest perfectly symmetric compromises in content to provide such chaining. However, this is not an impossible configuration, only unlikely, for it would suggest half the parties of each MFA pivot and carry content into the next agreement.

One situation in which it may be more likely is where one MFA amends another, which often entails quite similar text (but for the amendments) and very similar state parties. But even under these conditions, we would expect clustering to be 
especially embedded around particularly popular, closely related treaty texts. A standard TriangleXBX configuration would not capture this embedding of bipartite clustering around similar treaty texts, even when accounting for denser areas of bipartite clustering through a geometrically-weighted term (see Fig. 8(c)).

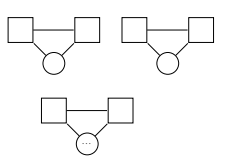

(a) Disembedded TriangleXBX

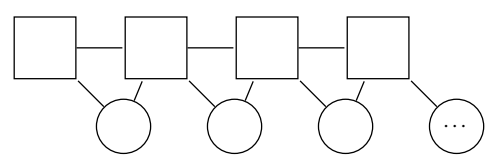

(b) Chained TriangleXBX
Figure 9: Disembedded similar choices: Impossible and counterfactual stylised networks implied by effect of similar choices that are not embedded in shared similar choices

Accordingly, we include TriangleXBX's alternating form, ATXBX (Fig. 8(d)). When including this effect we would expect the general tendency for states similar choices in MFAs (TriangleXBX) and for states to cluster their multilateral ties together (GW Shared A Nodes) to be both negative. In other words, states do not just choose any MFA similar to one they are currently a member of, nor do they just join any MFA that co-members of other MFAs have joined, but they join MFAs that are both similar and socially confirmed through their existing partners joining, such as in the case of amendments or other treaty developments.

\subsection{Cross-Level Clustering}

In the past two sub-sections, we have presented ways in which we would expect interlocked bipartite networks to affect unipartite clustering and interlocked unipartite networks to affect bipartite clustering in the context of global fisheries governance. But with three networks it may be that all three networks are aligned in terms of the kind of configuration shown in Fig. 10(a). Substantively, such alignment would indicate that bilateral and multilateral ties are aligned around similar content. Such an effect has been proffered as demonstrative of the power of multilevel network analysis for the study of network governance (see Bodin and Tengö, 2012; Wang et al., 2013b). Where such closure appears positive and significant, controlling for the kinds of opportunities for closure depicted in Fig. 10(b), this work suggests that this may be evidence of so-called 'multilevel alignment'.

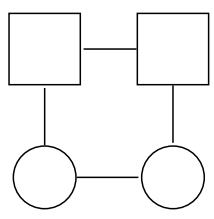

(a) Multilevel

Alignment

(C4AXB)

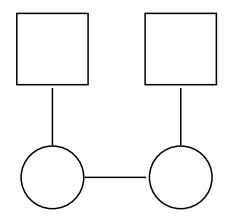

(b) 3-Path

(L3XAX)
Figure 10: Cross-Network Effects
However, this is not our assumption here. In the current context, such an effect would seem to suggest that the states establish bilateral agreements over the same issues as the MFAs; that there is an alignment between the content of the two levels. As argued above, BFAs typically play quite a different role to the more cost-efficient MFAs by providing parties with the opportunity to negotiate special terms. From this reasoning, we hypothesise that there will be no effect for multilevel alignment. A positive effect for cross-level closure (Fig. 5(c)), could be misinterpreted as alignment but we suggest that this effect ought to be instead interpreted as evidence for states employing bilateral agreements to negotiate special arrangements ancillary to multilateral agreements, not that the content is particularly aligned. Cross-level alignment would reflect interest overlap between the states' use of BFAs and MFAs, but we do not expect to see such configurations here.

\section{Results}

This section presents the results from using exponential random graph models to study clustering in and between the three component networks of the multilevel global fisheries governance complex. We fit three models: a bipartite model without the secretariat choices, a model where networks are independent, and a multilevel ERGM with cross-level effects. All models are estimated using standard procedures in MPNet (Lusher et al., 2013). The maximum likelihood estimates for the models are provided in table 1 .

\subsection{Goodness-of-fit}

We assess the goodness-of-fit of the final model, the Multilevel model of Table 1, by comparing the full suite of nonestimated statistics available in MPNet from the observed networks with a number (1000) of networks simulated using the parameter estimates from the fitted model. All cross-level statistics are well replicated. Judging by the predictive goodness-of-fit distributions in Fig. 11, the multilevel model manages to capture the degree distributions reasonably well, and sufficient for our purposes (Robins and Lusher, 2013, 184-185). The distributions for $A A$ and $B B$ are better described by the model than the degree distributions for the bipartite $x_{A B}$ though. Yet, the coarseness of $B$-nodes' degrees gives the impression that the fit is worse than it is. The underfit of degree three nodes is for example compensated by an overfit of degree four nodes. The observed (bipartite) degrees of the $A$-nodes is similarly irregular and poorly fitted by a smooth function. One issue with fitting this data was the $A$-isolates, something which is clearly visible from the plot (the observed statistic was only three, making any model with $A$ isolates in it highly unstable - this statistic also has a t-value of -5.4). For particular degree-related goodness-of-fit statistics, higher order stars 3-5 for the $A A$ network are underfitted and, for the $A B$ network, both higher order $A$-stars (highest t-statistic 3.7) and higher order $B$-stars (largest t-statistic in absolute value 3.1) are underfitted.

For non-degree related statistics, the goodness-of-fit shows a good fit with the exception of some of the bipartite configurations. For the subgraphs corresponding to bipartite clustering 


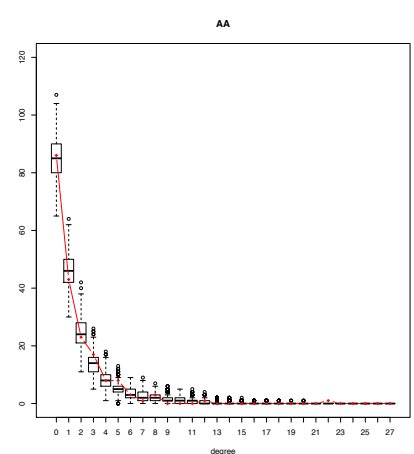

BA
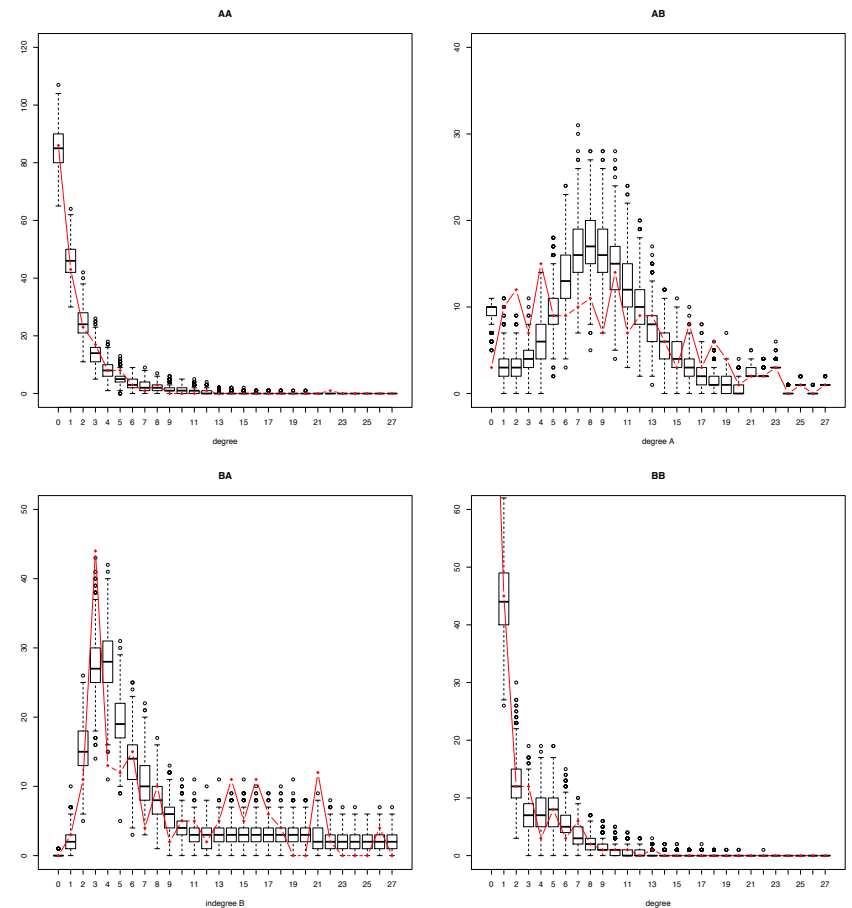

вв

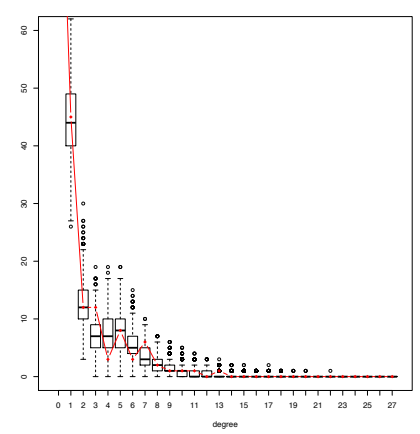

Figure 11: Multilevel Model Fit: The (out-) degree distributions for $A A, A B$, $B A$, and $B B$. Predictive frequencies given by boxes and observed values given by red triangles

bipartite 3-path and geometrically weighted shared $B$-nodes have t-statistics of -3.5 and -5.1 , respectively. Wang et al. (2013a) derive the statistics XECA and XECB out of a system of dependence assumptions. These configurations are not well captured by our model with GOF statistics of -2.4 and -3.6 respectively. It is possible in principle that model fit may be improved by including these but, admittedly, these are high-order interactions that are hard to theorise and interpret in the context of our example. Furthermore, while their alternating forms (XAECA and XAECB) are probably easier to fit, they are already well fit by the model $(-0.20$ and -0.18$)$. There are also some higher-order interactions of degree and clustering with GDP that indicate poor fit (for example the statistic gdpA_X2StarBDifference-a statistic that counts the pairwise differences in GDP between states affiliated to the same MFA - has the worse fit of these with a GOF statistic of -3.9).

Having discussed the goodness-of-fit and found it generally satisfactory but for some more complex statistics, we proceed by interpreting and commenting on the results thematically. Some effects, such as the degree-related effects AS and ASA, are included as controls and to assist model fit but are not themselves target for interpretation. Note also that we have fixed the density in the $B B$ network and set the tuning constant $\lambda=4$ for the alternating triangle effect $\mathrm{AT}$ in the model for $B B$ to improve the fit and assist convergence.

\subsection{Nodal covariates}

First, we find that monadic covariates for states in the $A A$ and $A B$ networks are in line with the notion that bilateral and multilateral instruments are employed in different contexts. States that fish a lot by volume are more likely to form bilateral agreements, which is as we would expect, but it seems that larger states (measured by logged GDP) make bilateral fisheries agreements (coefficient 1.53) and smaller states make multilateral fisheries agreements (coefficient -0.95). When smaller states do make BFAs, it tends to be with a larger partner (GDP heterophily coefficient 2.15). But while GDP facilitates bilateral activity, we find that states' experience of threatened species within their domestic waters motivates their joining MFAs but has no effect on bilateral ties. Read together, these results are consistent with the notion that bilateral and multilateral instruments are used for different purposes: BFAs are often used instrumentally by larger states to gain access to the coastal resources of smaller states, whereas multilateral instruments are used by states, including smaller states, to address shared concerns about threats to historical resources.

When we include the multilevel or cross-level effects in model 3, the activity effect for GDP in the bilateral network disappears. This may indicate that the negative association between $A A$-degree and $A B$-degree (Star2AX) is driven by wealthy states.

\subsection{One-mode clustering}

Next we find our hypothesis for one-mode clustering confirmed. This is important. In the independent model, we find a positive and significant effect with a parameter 0.37 for clustering AT in the $A A$ network (Fig. 5(b)). When the cross-level effects are added in the Multilevel model however, the parameter is reduced to 0.23 which is statistically non-significant. Due to the high degree of interdependence of effects, it is difficult to isolate exactly which cross-level effect is responsible for weakening AT, but the most likely candidate for a moderator is cross-level closure (TriangleXAX; Fig.. 5(c)).

Sometimes geospatial embedding is put forward as a clustering mechanism that potentially confounds structural (i.e. endogenous) effects (Butts, 2003; Butts and Acton, 2011; Hoff et al., 2002). In the Independent model we do however see an effect for both endogenous clustering and distance. This effect is significant and negative, meaning that the likelihood of a bilateral fisheries agreement generally diminishes with distance (according to an approximate power-law) (Daraganova et al., 2012).

By contrast, the one-mode clustering (AT) of MFAs in the $B B$ network (Fig. 6(b)) is positive and significant in both the Independent model and the Multilevel model. Indeed, the parameter and standard error are virtually unaffected by the inclusion of cross-level effects. The alternating triangle edge parameter AET ( Fig.. 6(c) ) is negative and significant in both the Independent and the Multilevel model, and thus unaffected by cross-level effects.

\subsection{Bipartite and Multilevel clustering}

As bipartite clustering in the form of four-cycles is such a potentially important form of clustering we have fit a separate Bipartite model (first column of table 1). The alternating four-cycle statistic (alternating on states as in the Fig.. 8(b)) is 


\begin{tabular}{|c|c|c|c|c|c|c|c|c|c|c|}
\hline \multirow[b]{3}{*}{$A A$} & \multirow[b]{2}{*}{ Effects } & \multicolumn{3}{|c|}{ Bipartite } & \multicolumn{3}{|c|}{ Independent } & \multicolumn{3}{|c|}{ Multilevel } \\
\hline & & Parameter & S.E. & & Parameter & S.E. & & Parameter & S.E. & \\
\hline & Edge & & & & 3.73 & 0.77 & * & 5.19 & 1.23 & * \\
\hline & Alternating star (AS) & & & & 0.52 & 0.13 & * & 0.37 & 0.14 & * \\
\hline & Alternating triangle (AT) & & & & 0.37 & 0.11 & * & 0.23 & 0.12 & \\
\hline & GDP (log) capacity (activity) & & & & 1.53 & 0.64 & * & 0.41 & 0.81 & \\
\hline & GDP (log) heterophily (difference) & & & & 2.15 & 1.05 & * & 2.72 & 1.19 & * \\
\hline & Threatened species sum (activity) & & & & 0.05 & 0.03 & & 0.03 & 0.03 & \\
\hline & Threatened species product (product) & & & & -0.01 & 0.01 & & 0.00 & 0.01 & \\
\hline & Fishing volume (activity) & & & & 0.15 & 0.02 & * & 0.17 & 0.03 & * \\
\hline & Fishing difference (difference) & & & & -0.01 & 0.03 & & 0.06 & 0.04 & \\
\hline & Distance $(\log )$ & & & & -1.30 & 0.10 & * & -1.23 & 0.11 & * \\
\hline$B B$ & 2-star & & & & -0.13 & 0.09 & & -0.13 & 0.10 & \\
\hline & Isolate & & & & -0.99 & 0.79 & & -0.96 & 0.80 & \\
\hline & Alternating star (AS) & & & & 0.34 & 0.51 & & 0.31 & 0.52 & \\
\hline & Alternating triangle $(\lambda=4)(\mathrm{AT})$ & & & & 2.46 & 0.24 & * & 2.46 & 0.25 & * \\
\hline & Alternating independent 2-path (A2P) & & & & 0.11 & 0.11 & & 0.11 & 0.11 & \\
\hline & Alternating edge-triangle (AET) & & & & -0.21 & 0.09 & $*$ & -0.21 & 0.09 & * \\
\hline$A B$ & Edge & -2.13 & 0.95 & * & -2.30 & 0.91 & * & -2.01 & 0.95 & * \\
\hline & Alternating star ( $A$-degree ASA $)$ & 3.25 & 0.32 & * & 2.74 & 0.31 & * & 2.61 & 0.32 & * \\
\hline & Alternating star ( $B$-degree ASB) & -3.33 & 0.43 & * & -3.34 & 0.45 & * & -3.35 & 0.46 & * \\
\hline & GW shared $A$-nodes (ACA) & -0.55 & 0.03 & * & -0.45 & 0.04 & * & -0.45 & 0.04 & * \\
\hline & Secretariat (XEdgeA) & & & & 0.88 & 0.13 & * & 0.82 & 0.13 & * \\
\hline & Shared (secretariat) choices (X4CycleB1) & & & & 0.004 & 0.001 & * & 0.004 & 0.001 & * \\
\hline & GDP $(\log )$ capacity (activity) & -0.94 & 0.50 & & -0.95 & 0.46 & * & -0.87 & 0.45 & \\
\hline & Threatened species sum (activity) & 0.16 & 0.02 & $*$ & 0.13 & 0.02 & * & 0.13 & 0.02 & $*$ \\
\hline$X$ & Activity correspondence (Star2AX) & & & & & & & -0.94 & 0.30 & * \\
\hline & Asymmetric activity (StarAX1A) & & & & & & & 0.46 & 0.15 & * \\
\hline & Cross-level closure (TriangleXAX) & & & & & & & 0.09 & 0.02 & * \\
\hline & 3-Path (L3XAX) & & & & & & & 1.18 & 0.33 & $*$ \\
\hline & Activity correspondence (Star2BX) & & & & & & & 0.001 & 0.003 & \\
\hline & Cross-level closure (TriangleXBX) & & & & & & & -0.21 & 0.09 & * \\
\hline & Alt. closure (ATXBX) & & & & & & & 0.001 & 0.0000 & * \\
\hline & Multilevel alignment (C4AXB) & & & & & & & 0.00 & 0.01 & \\
\hline
\end{tabular}

Table 1: Multilevel ERGM parameter estimates for Multilateral Fisheries Agreements. Asterix (*) denotes a parameter that is twice the size of its standard error. The models are estimated using MPNet (MPNet terms in parentheses when needed for clarity).

negative and significant (closure alternating on MFAs was poorly fit according to the GOF but both alternating forms were not possible to fit, something that has been reported in other bipartite analyses (e.g. Harrigan and Bond, 2013)). The goodness-of-fit for the Bipartite model indicates that its effects are not sufficient for capturing four-cycles (GOF t-statistic: 2.03). When the two effects for secretariat nodes, 'Secretariat' and 'Shared Managed (Sec) Choices', are included the lower-order four-cycle is well captured. That these two effects account for bipartite clustering is also reflected in a slight reduction in the negative coefficient for the geometrically weighted (GW) shared choices (ACA). ACA is however negative and significant in all three models suggesting that there is tendency against states clustering around common choices, over and above the other effects.

Cross-level closure of $A A$-ties (TriangleXAX) in the multilevel model is positive and significant and as noted above the effect likely to explain one-mode clustering in the $A A$ network. The other cross-level closure effects have the predicted signs. Cross-level closure of $B B$-ties (TriangleXBX) is negative while 'Similar Multilateral Clustering' (ATXBX) is positive and significant. Multilevel alignment is not statistically significantly different from zero. Thus we have states sign up to MFAs that are similar but only if these structures are embedded in multiple similar choices, reflecting that the MFAs are collectively constituted, and there is no evidence of overlap between the bilateral and the multilateral interests.

\section{Discussion}

This paper has demonstrated how ties' being embedded in a multilevel structure of interlocking networks affects the propensity of ties to cluster in certain configurations. Chief among our 
findings is that a finding that states' bilateral ties cluster in a model that treats these ties as independent can instead be explained by patterns of common multilateral affiliation. This is not simply a function of the additional complexity introduced by including multiple networks though: the clustering of multilateral fisheries agreements by similar content is not explained by states' shared choices in either bilateral or multilateral treaties. This finding demonstrates the added insight in considering interlocking bipartite networks of groups or settings when interpreting unipartite clustering.

Our paper has also shown how multilevel modelling can improve our ability to explain bipartite clustering. While fourcycles have been proposed as an important form of clustering for bipartite network structure and evolution (Robins and Alexander, 2004; Borgatti and Everett, 1997), they have proven consistently difficult to fit (Wang, 2006) and alternating forms of four-cycles have often been found negative in ERGMs (Harrigan and Bond, 2013; Niekamp et al., 2013; Lubell et al., 2014). These findings seem difficult to reconcile with the notion that social groups are typically characterised by positive tendencies to cluster or overlap in the choice of groups (Robins and Alexander, 2004; Koskinen and Edling, 2012). We have found though that, by parametrising bipartite clustering as agglomerating around nodes with particular attributes (such as having a secretariat which provides a forum or setting for further collaboration, Lubell et al. (see also 2014)) and accounting for how actors cluster around similar multilateral institutions (operationalised as a toplevel unipartite network relating multilateral agreements to one another), we have both fit and explained how an alternating form of four-cycles might be negative but one that is itself clustered around similar multilateral agreements is positive. We believe that how second-mode targets differentially provide sites for clustering, and are themselves related, may apply more generally in bipartite networks.

This paper is hardly the final word on multilevel embedding. To start with, we have focused here only on the more common "small fish" of states that are more typically active in each network, fixing both particularly active states and particularly popular MFAs. How the most active states, the "big fish", experience, generate, and manage multilevel embedding will need to be explored more in future studies. Future research should also explore how common our finding of an absence of multilevel alignment, which is unexpected in the network governance literature, is in network governance. Here we have explained how the absence of this effect reflects how bilateral and multilateral instruments are used for different purposes in global fisheries governance: whereas multilateral fisheries agreements tend to concern the establishment of collective norms for sustainable fishing of shared fish stocks, bilateral fisheries agreements tend to be about defining and delimiting resource access.

How has this exercise in multilevel modelling improved our understanding of global fisheries governance? The clear narrative provided by the results is one in which bilateral and multilateral instruments represent different but interdependent choices. Bilateralism appears to be the preferred choice of larger (by GDP), fishing-intensive states, especially vis-a-vis smaller partners, whereas multilateral agreements appear to be more popular among smaller states, and especially those with experience of local marine stocks being threatened. This observation is in line with common realist, liberal and constructivist theories of International Relations. For realist scholars, multilateral instruments provide smaller states with the ability to collectively balance the power of individually powerful states. For liberal scholars, multilateral instruments provide smaller states, which may not be able to afford the costs associated with having many agreements, with a more efficient coordination instrument. Lastly, for constructivist scholars, multilateral instruments allow the many smaller states in the contemporary state system with the ability to define (regional) community norms of resource management and conservation. That these multilateral fisheries agreements are clustered in terms of content similarity suggests that the proliferation of multilateral fisheries agreements does not suggest fragmentation necessarily but rather that states are becoming more deeply embedded in multilateral structures.

The residual reliance on bilateralism is important though, because some of the most poorly managed fish stocks are collective problems that concern more than two parties (Hardin, 1968; Ostrom, 1990; Diez et al., 2002) and for which international cooperation is required (Shaw, 2003, 771). Whether bilateralism is problematic here remains an open question. Creating bilateral arrangements that exclude other potentially relevant parties may impact the long-term viability and effectiveness of an arrangement (in the context of water management see $\mathrm{Za}$ wahri and Mitchell, 2011, 837). Alternatively, bilateralism may enhance global and regional governance efforts where they are complementary to multilateral agreements such as in the case of the nuclear proliferation regime (Verdier, 2008). What we do now know is that, while bilateral fisheries agreements do cluster in triads (Kinne, 2013), this bilateral clustering emanates from their embedding in a multilevel structure that also includes states' multilateral fisheries agreements.

\section{References}

Agneessens, F., Roose, H., Jul. 2008. Local Structural Properties and Attribute Characteristics in 2-mode Networks: p Models to Map Choices of Theater Events. The Journal of Mathematical Sociology 32 (3), 204-237.

Barkin, J. S., DeSombre, E. R., 2000. Unilateralism and Multilateralism in International Fisheries Management. Global Governance 6, 339-360.

Berardo, R., Scholz, J. T., Jul. 2010. SelfOrganizing Policy Networks: Risk, Partner Selection, and Cooperation in Estuaries. American Journal of Political Science 54 (3), 632-649.

Bodin, Ö., Tengö, M., Mar. 2012. Disentangling intangible social-ecological systems. Global Environmental Change, 1-10.

Borgatti, S. P., Everett, M. G., 1997. Network analysis of 2-mode data. Social Networks 19 (3), 243-269.

Breiger, R. L., 1974. The duality of persons and groups. Social Forces 53, 181-190.

Butts, C. T., 2003. Predictability of Large-scale Spatially Embedded Networks. In: Breiger, R. L., Carley, K. M., Pattison, P. E. (Eds.), Dynamic Social Network Modelling and Analysis: Workshop Summary and Papers. The National Academies Press, Washington, DC, pp. 313-323.

Butts, C. T., Acton, R. M., 2011. Spatial modeling of social networks. In: Nyerges, T. L., Coucleis, H., McMaster, R. (Eds.), The SAGE Handbook of GIS and Society. Sage, London, pp. 222-250.

Carr, C. L., Scott, G. L., 1999. Multilateral Treaties and the Environment: A Case Study in the Formation of Customary International Law. Denver Journal of International Law and Policy 27 (2), 313-335. 
Cartwright, D., Harary, F., 1956. Structural balance - A generalization of Heider's theory. Psychological Review 63 (5), 277-293.

Chalamish, E., Apr. 2009. The Future of Bilateral Investment Treaties: A De Facto Multilateral Agreement? Brook. J. Int'1 L. 34 (2), 303-354.

Daraganova, G., Pattison, P. E., Koskinen, J. H., Mitchell, B., Bill, A., Watts, M., Baum, S., Jan. 2012. Networks and geography: Modelling community network structures as the outcome of both spatial and network processes. Social Networks 34 (1), 6-17.

Davis, J. A., 1970. Clustering and hierarchy in interpersonal relations: Testing two graph theoretical models on 742 sociomatrices. American Sociological Review, 843-851.

Diez, T., Dolsak, N., Ostrom, E., Stern, P. C., Mar. 2002. The Drama of the Commons. In: The Drama of the Commons. National Academy Press, Washington, DC, pp. 1-32.

ECOLEX, 2011. The Gateway to Environmental Law.

URL http: //www . ecolex . org/start.php

FAO, 2011. FishStatJ - software for fishery statistical time series.

Festinger, L., Schachter, S., Back, K., 1950. The Spatial Ecology of Group Formation. In: Festinger, L., Schachter, S., Back, K. (Eds.), Social Pressure in Informal Groups. Stanford University Press, Palo Alto, CA, pp. 33-60.

Frank, O., Strauss, D., Sep. 1986. Markov Graphs. Journal of the American Statistical Association 81 (395), 832-842.

Froese, R., Pauly, D., 2008. Fishbase Database. www.fishbase.org.

Granovetter, M. S., May 1973. The Strength of Weak Ties. The American Journal of Sociology 78 (6), 1360-1380.

Hardin, G., Dec. 1968. The Tragedy of the Commons. Science 162 (3859), 1243-1248.

Harrigan, N., Bond, M., 2013. Differential Impact of Directors' Social and Financial Capital on Corporate Interlock Formation. In: Lusher, D., Koskinen, J. H., Robins, G. L. (Eds.), Exponential Random Graph Models: Theory, Methods, and Applications. Cambridge University Press, Cambridge, UK, pp. 260-283.

Hoff, P. D., Raftery, A. E., Handcock, M. S., 2002. Latent space approaches to social network analysis. Journal of the American Statistical Association 97 (460), 1090-1098.

Holland, P. W., Leinhardt, S., Nov. 1970. A Method for Detecting Structure in Sociometric Data. The American Journal of Sociology 76 (3), 492-513.

Hornik, K., Mair, P., Rauch, J., Geiger, W., Buchta, C., Feinerer, I., 2013. The textcat Package for n-Gram Based Text Categorization in R. Journal of Statistical Software 52 (6), 1-17.

Jupille, J., Mattli, W., Snidal, D., Jan. 2013. Institutional Choice and Global Commerce. Cambridge University Press, Cambridge, UK

Kim, R. E., Oct. 2013. The emergent network structure of the multilateral environmental agreement system. Global Environmental Change 23 (5), 980991

Kinne, B. J., Oct. 2013. Network Dynamics and the Evolution of International Cooperation. The American Political Science Review 107 (04), 766-785.

Koskinen, J. H., Edling, C., Jul. 2012. Modelling the evolution of a bipartite network-Peer referral in interlocking directorates. Social Networks 34 (3), 309-322.

Koskinen, J. H., Lomi, A., Mar. 2013. The Local Structure of Globalization. Journal of statistical physics, 1-26.

Lazega, E., Jourda, M.-T., Mounier, L., Stofer, R., May 2008. Catching up with big fish in the big pond? Multi-level network analysis through linked design. Social Networks 30 (2), 159-176.

Lubell, M., Robins, G. L., Wang, P., 2014. Network structure and institutional complexity in an ecology of water management games. Ecology and Society 19 (4), art23.

Lusher, D., Koskinen, J. H., Robins, G. L. (Eds.), 2013. Exponential Random Graph Models for Social Networks: Theory, Methods and Applications. Cambridge University Press, Cambridge, UK.

Mitchell, R. B., Jul. 2013. International Environmental Agreements Database Project (Version 2013.2). University of Oregon.

Moody, J., White, D. R., Feb. 2003. Structural Cohesion and Embeddedness: A Hierarchical Concept of Social Groups. American Sociological Review 68 (1), 103-127.

Moreno, J., Jennings, H., 1938. Statistics of Social Configurations. Sociometry $1(3 / 4), 342-374$.

Niekamp, A.-M., Mercken, L. A. G., Hoebe, C. J. P. A., Dukers-Muijrers, N. H. T. M., Mar. 2013. ARTICLE IN PRESS. Social Networks, 1-14.

Opsahl, T., Aug. 2011. Triadic closure in two-mode networks: Redefining the global and local clustering coefficients. Social Networks 35 (2), 159-167.

Opsahl, T., Panzarasa, P., May 2009. Clustering in weighted networks. Social Networks 31 (2), 155-163.

Ostrom, E., 1990. Governing the Commons: The Evolution of Institutions for Collective Action. Cambridge University Press, Cambridge, UK.

Pattison, P. E., Snijders, T. A. B., 2013. Modeling Social Networks: Next Steps. In: Lusher, D., Koskinen, J. H., Robins, G. L. (Eds.), Exponential Random Graph Models for Social Networks: Theory, Methods, and Applications. Cambridge University Press, Cambridge, UK, pp. 287-301.

Pauwelyn, J., Nov. 2003. A Typology of Multilateral Treaty Obligations: Are WTO Obligations Bilateral or Collective in Nature? European Journal of International Law 14 (5), 907-951.

Petersen, E., May 2003. The catch in trading fishing access for foreign aid. Marine Policy 27 (3), 219-228.

Provan, K. G., Kenis, P. N., Jun. 2007. Modes of Network Governance: Structure, Management, and Effectiveness. Journal of Public Administration Research and Theory 18 (2), 229-252.

Provan, K. G., Milward, H. B., Mar. 1995. A Preliminary Theory of Interorganizational Network Effectiveness: A Comparative Study of Four Community Mental Health Systems. Administrative Science Quarterly 40 (1), 1-33.

Robins, G. L., Alexander, M., 2004. Small worlds among interlocking directors: Network structure and distance in bipartite graphs. Computational \& Mathematical Organization Theory 10 (1), 69-94.

Robins, G. L., Bates, L., Pattison, P. E., 2011. Network governance and environmental management: conflict and cooperation. Public Administration 89 (4), 1293-1313.

Robins, G. L., Lusher, D., 2013. Illustrations: Simulation, Estimation, and Goodness of Fit. In: Exponential Random Graph Models for Social Networks: Theory, Methods, and Applications. Cambridge University Press, Cambridge, UK, pp. 167-185.

Schweinberger, M., Handcock, M. S., 2012. Hierarchical Exponential-Family Random Graph Models With Local Dependence.

Shaw, M. N., 2003. International Law. Cambridge University Press, Cambridge, UK.

Simmel, G., 1955. Conflict and the Web of Group-Affiliations. Free Press, New York, NY.

Skvoretz, J., Faust, K., 1999. Logit models for affiliation networks. Sociological Methodology 29 (1), 253-280.

Snijders, T. A. B., Pattison, P. E., Robins, G. L., Handcock, M. S., Dec. 2006. New Specifications for Exponential Random Graph Models. Sociological Methodology 36 (1), 99-153.

Verdier, D., Jul. 2008. Multilateralism, Bilateralism, and Exclusion in the Nuclear Proliferation Regime. International Organization 62 (3), 439-476.

Wang, P., Oct. 2006. Exponential Random Graph (p*) Models for Affiliation Networks. Ph.D. thesis, University of Melbourne.

Wang, P., Pattison, P. E., Robins, G. L., May 2013a. Exponential random graph model specifications for bipartite networks: A dependence hierarchy. Social Networks 35 (2), 211-222.

Wang, P., Robins, G. L., Pattison, P. E., Lazega, E., Jan. 2013b. Exponential random graph models for multilevel networks. Social Networks 35 (1), 96115.

Wang, P., Sharpe, K., Robins, G. L., Pattison, P. E., 2009. Exponential random graph (p) models for affiliation networks. Social Networks 31, 12-25.

Wasserman, S., Iacobucci, D., 1991. Statistical modelling of one mode and two mode networks: Simultaneous analysis of graphs and bipartite graphs. British Journal of Mathematical and Statistical Psychology 44 (1), 13-43.

Witbooi, E., 2008. The infusion of sustainability into bilateral fisheries agreements with developing countries: The European Union example. Marine Policy 32, 669-679.

Xue, G., 2005. Bilateral Fisheries Agreements for the Cooperative Management of the Shared Resources of the China Seas: A Note. Ocean Development and International Law 36 (4), 363-374.

Zawahri, N. A., Mitchell, S. M., 2011. Fragmented Governance of International Rivers: Negotiating Bilateral versus Multilateral Treaties. International Studies Quarterly 55, 835-858.

Zelli, F., van Asselt, H., Aug. 2013. Introduction: The Institutional Fragmentation of Global Environmental Governance: Causes, Consequences, and Responses. Global Environmental Politics 13 (3), 1-13. 